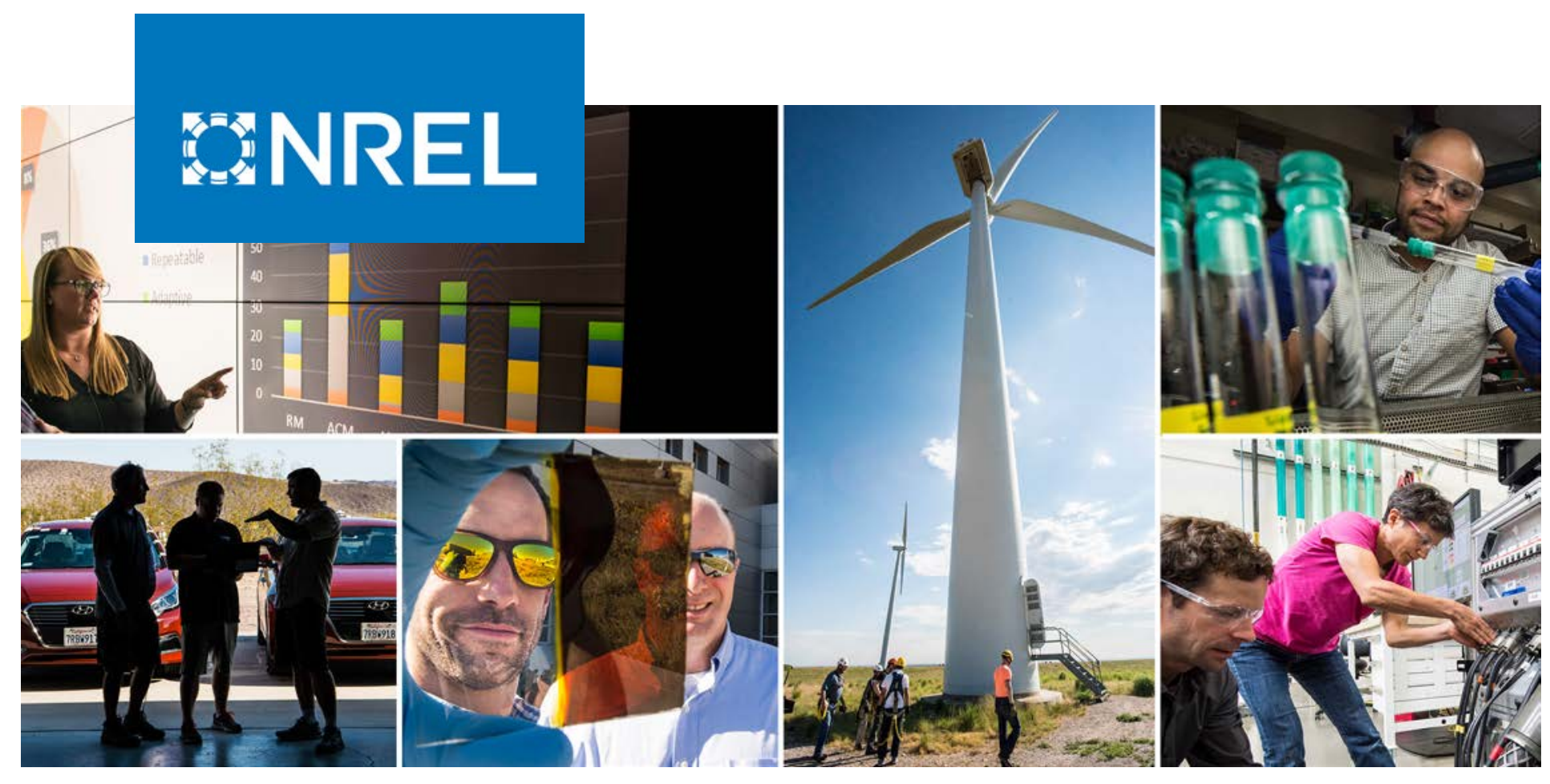

\title{
Assessment of BQ-9000 Biodiesel Properties for 2017
}

\author{
Teresa L. Alleman
}

National Renewable Energy Laboratory

Produced under direction of the National Biodiesel Board by the National Renewable Energy Laboratory (NREL) under CRADA agreement number CRD-15-593.

NREL is a national laboratory of the U.S. Department of Energy Office of Energy Efficiency \& Renewable Energy

Operated by the Alliance for Sustainable Energy, LLC

This report is available at no cost from the National Renewable Energy Laboratory (NREL) at www.nrel.gov/publications.
Strategic Partnership Project Report NREL/TP-5400-75795

January 2020 


\title{
GANEL
}

\section{Assessment of BQ-9000 Biodiesel Properties for 2017}

\author{
Teresa L. Alleman
}

National Renewable Energy Laboratory

\section{Suggested Citation}

Alleman, Teresa L. 2020. Assessment of BQ-9000 Biodiesel Properties for 2017.

Golden, CO: National Renewable Energy Laboratory. NREL/TP-5400-75795.

https://www.nrel.gov/docs/fy20osti/75795.pdf.

NREL is a national laboratory of the U.S. Department of Energy Office of Energy Efficiency \& Renewable Energy Operated by the Alliance for Sustainable Energy, LLC

This report is available at no cost from the National Renewable Energy Laboratory (NREL) at www.nrel.gov/publications.

Contract No. DE-AC36-08GO28308
Strategic Partnership Project Report NREL/TP-5400-75795 January 2020

National Renewable Energy Laboratory 15013 Denver West Parkway Golden, CO 80401 303-275-3000 • www.nrel.gov 


\section{NOTICE}

This work was authored by the National Renewable Energy Laboratory, operated by Alliance for Sustainable Energy, LLC, for the U.S. Department of Energy (DOE) under Contract No. DE-AC36-08G028308. Support for the work was also provided by the National Biodiesel Board under CRADA agreement number CRD-15-593. The views expressed in the article do not necessarily represent the views of the DOE or the U.S. Government. The U.S. Government retains and the publisher, by accepting the article for publication, acknowledges that the U.S. Government retains a nonexclusive, paid-up, irrevocable, worldwide license to publish or reproduce the published form of this work, or allow others to do so, for U.S. Government purposes.

This report is available at no cost from the National Renewable Energy Laboratory (NREL) at www.nrel.gov/publications.

U.S. Department of Energy (DOE) reports produced after 1991 and a growing number of pre-1991 documents are available free via www.OSTI.gov.

Cover Photos by Dennis Schroeder: (clockwise, left to right) NREL 51934, NREL 45897, NREL 42160, NREL 45891, NREL 48097, NREL 46526.

NREL prints on paper that contains recycled content. 


\section{Acknowledgments}

The author wishes to thank the National Biodiesel Board for funding support for this work under Cooperative Research and Development Agreement CRD-15-593. Technical support was provided by Mr. Steve Howell of M4 Consulting, Mr. Scott Fenwick of the National Biodiesel Board, and Dr. Richard Nelson of Enersol Resources. 


\section{List of Acronyms}

AGQM

AOCS

ASTM

B100

CSFT

EN

MG

NBB

NREL
Association Quality Management Biodiesel (Germany)

American Oil Chemist's Society

ASTM International

neat biodiesel

cold soak filterability test

European Standard

monoglycerides

National Biodiesel Board

National Renewable Energy Laboratory 


\section{Executive Summary}

This is the first in a series of annual reports tracking the quality of neat biodiesel (B100) produced and sold in the United States. The data covers biodiesel produced and sold in the United States by companies that participate in the biodiesel industry's voluntary quality program, BQ-9000. Data were voluntarily provided and scrubbed of identifying information before being randomized. This report covers the National Renewable Energy Laboratory's analysis of that data, which includes 5,391 unique data points on over 400 lots of biodiesel from the United States and Canada produced and sold in calendar year 2017.

The analytical results summarized in this report are as follow, and data and statistics are summarized in Table ES-1.

- $\quad$ Sodium and potassium, combined $(\mathrm{Na}+\mathrm{K})$

- Calcium and magnesium, combined $(\mathrm{Ca}+\mathrm{Mg})$

- Phosphorus (P)

- Flash point or alcohol control

- Water and sediment

- Cloud point

- Acid number

- Free glycerin

- Total glycerin

- Monoglycerides (MG)

- Sulfur (S)

- Oxidation stability

- Visual appearance

- Cold soak filterability test (CSFT). 
Table ES-1. BQ-9000 Critical Parameter Summary Table, Calendar Year 2017

\begin{tabular}{|c|c|c|c|c|c|c|c|}
\hline $\begin{array}{l}\text { BQ-9000 } \\
\text { Parameter }\end{array}$ & $\begin{array}{l}\text { \# of } \\
\text { values } \\
\text { reported }\end{array}$ & Minimum & Maximum & Average & Median & $\begin{array}{l}\text { Standard } \\
\text { Deviation }\end{array}$ & $\begin{array}{l}95^{\text {th }} \\
\text { percentile }\end{array}$ \\
\hline $\mathrm{Na}+\mathrm{K}, \mathrm{ppm}$ & 416 & 0 & 6.00 & 0.679 & 0.300 & 0.871 & 2.23 \\
\hline $\mathrm{Ca}+\mathrm{Mg}, \mathrm{ppm}$ & 408 & 0 & 4.00 & 0.301 & 0.057 & 0.568 & 2.00 \\
\hline $\mathrm{P}, \mathrm{ppm}$ & 354 & 0 & 10.0 & 0.411 & 0.00 & 1.81 & 1.00 \\
\hline Flash Point, ${ }^{\circ} \mathrm{C}$ & 385 & 95 & 211 & 155 & 160 & 22 & 180 \\
\hline $\begin{array}{l}\text { Alcohol Control, } \\
\text { mass \% }\end{array}$ & 163 & 0 & 0.14 & 0.06 & 0.06 & 0.043 & 0.135 \\
\hline $\begin{array}{l}\text { Water and } \\
\text { Sediment, vol\% }\end{array}$ & 315 & 0 & 0.020 & 0.002 & 0.00 & 0.004 & 0.01 \\
\hline Cloud Point, ${ }^{\circ} \mathrm{C}$ & 413 & -4.1 & 15 & 0.800 & -0.078 & 3.75 & 9 \\
\hline $\begin{array}{l}\text { Acid Number, } \\
\mathrm{mg} \mathrm{KOH} / \mathrm{g}\end{array}$ & 421 & 0.05 & 0.47 & 0.26 & 0.27 & 0.98 & 0.41 \\
\hline $\begin{array}{l}\text { Free Glycerin, } \\
\text { mass } \%\end{array}$ & 421 & 0 & 0.083 & 0.007 & 0.007 & 0.006 & 0.014 \\
\hline $\begin{array}{l}\text { Total Glycerin, } \\
\text { mass } \%\end{array}$ & 421 & 0.003 & 0.256 & 0.092 & 0.103 & 0.0417 & 0.151 \\
\hline $\begin{array}{l}\text { Monoglycerides, } \\
\text { mass \% }\end{array}$ & 421 & 0.001 & 0.800 & 0.271 & 0.299 & 0.122 & 0.436 \\
\hline Sulfur, ppm & 420 & 0 & 17.3 & 3.4 & 1.8 & 3.6 & 10.8 \\
\hline $\begin{array}{l}\text { Oxidation } \\
\text { Stability, hr. }\end{array}$ & 421 & 2.7 & 40.6 & 9.8 & 9.0 & 4.4 & 17.2 \\
\hline $\begin{array}{l}\text { Cold Soak } \\
\text { Filterability Test, } \\
\text { sec }\end{array}$ & 409 & 54 & 324 & 108 & 105 & 26 & 144 \\
\hline
\end{tabular}




\section{Table of Contents}

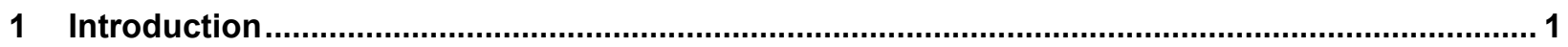

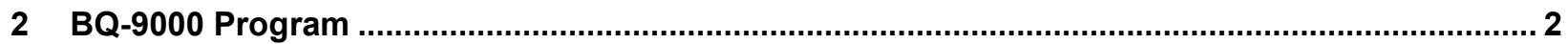

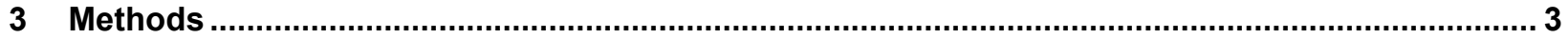

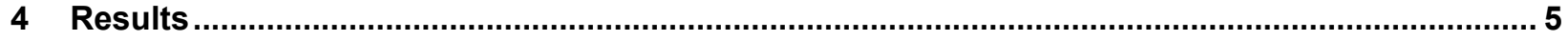

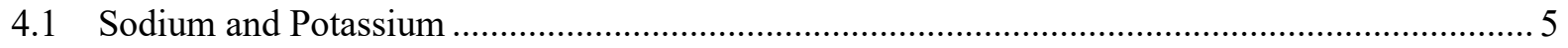

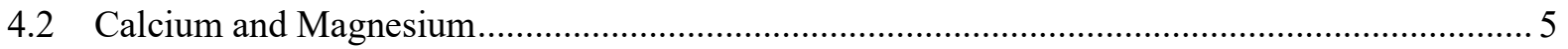

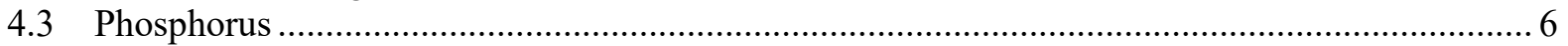

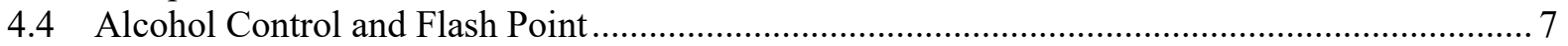

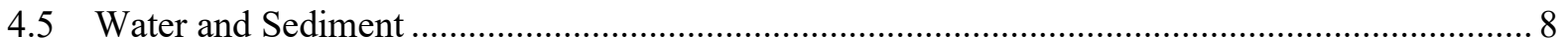

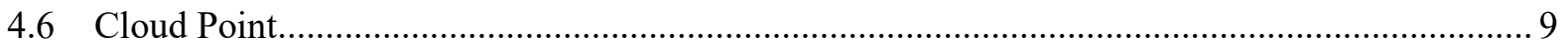

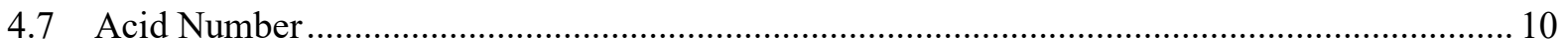

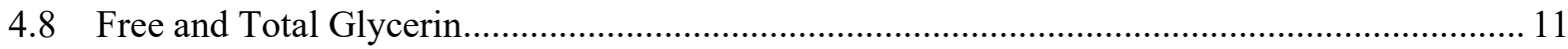

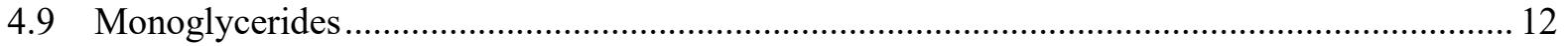

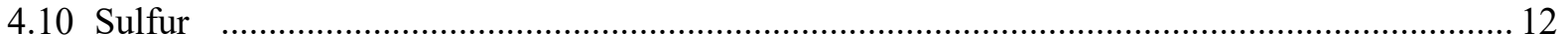

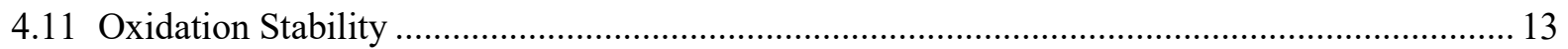

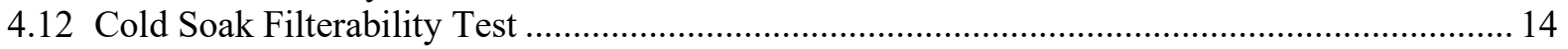

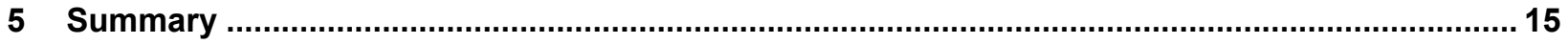

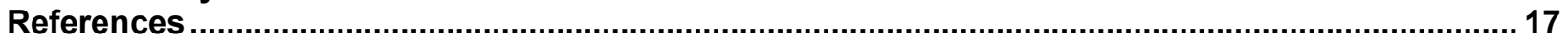

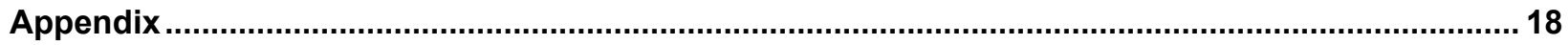




\section{List of Figures}

Figure 1. Sodium and potassium content of biodiesel samples, January-December 2017....................... 5

Figure 2. Calcium and magnesium content for biodiesel samples, January-December 2017 .................... 6

Figure 3. Phosphorus content for biodiesel samples, January-December 2017 ...................................... 6

Figure 4. Flash point for biodiesel samples, January-December 2017 ….......................................... 7

Figure 5. Methanol content for biodiesel samples, January-December 2017 ...................................... 8

Figure 6. Water and sediment for BQ-9000 producers, January-December 2017 ................................9

Figure 7. Cloud point for BQ-9000 producers, January-December 2017 .......................................... 10

Figure 8. Acid number for BQ-9000 producers, January-December 2017 ....................................... 10

Figure 9. Free glycerin for biodiesel samples, January-December 2017 ............................................ 11

Figure 10. Total glycerin for biodiesel samples, January-December 2017 ........................................ 11

Figure 11. Monoglyceride content for biodiesel samples, January-December 2017 ............................. 12

Figure 12. Sulfur content for biodiesel samples, January-December 2017 ........................................ 13

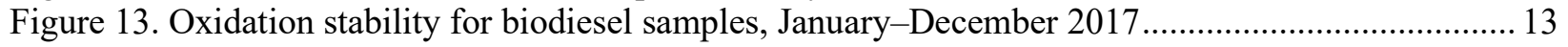

Figure 14. CSFT for biodiesel samples, January-December 2017 .................................................... 14

Figure A-1. All data analysis of sodium and potassium for B100 samples produced January-December 2017

Figure A-2. All data analysis of calcium and magnesium for B100 samples produced January-December

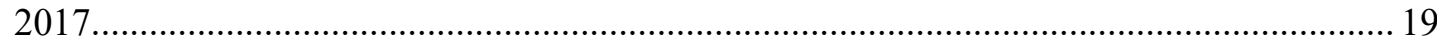

Figure A-3. All data analysis of P for B100 samples produced January-December 2017.....................20

Figure A-4. All data analysis of flash point for B100 samples produced January-December 2017.........20

Figure A-5. All data analysis of methanol content for B100 samples produced January-December 2017.

Figure A-6. All data analysis of water and sediment for B100 samples between January-December 2017.

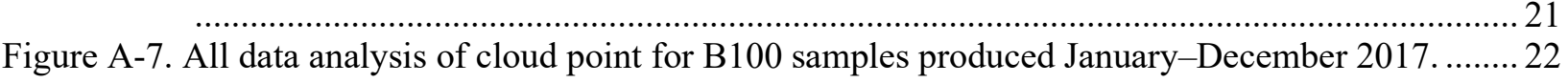
Figure A-8. All data analysis of acid number for B100 samples produced January-December 2017 ...... 22 Figure A-9. All data analysis of free glycerin for B100 samples produced January-December 2017 ...... 23 Figure A-10. All data analysis of total glycerin for B100 samples produced January-December 2017 ...23 Figure A-11. All data analysis of monoglycerides for B100 samples produced January-December 2017.24 Figure A-12. All data analysis of sulfur for B100 samples produced January-December 2017..............24 Figure A-13. All data analysis of oxidation stability for B100 samples produced January-December 2017.

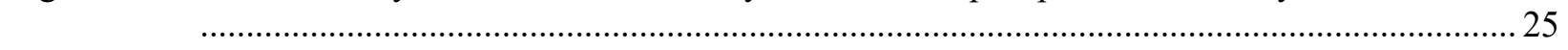

Figure A-14. All data analysis of CSFT for B100 samples produced January-December 2017.............. 25

\section{List of Tables}

Table ES-1. BQ-9000 Critical Parameter Summary Table, Calendar Year 2017 .....................................vi

Table 1. BQ-9000 Critical Parameter Summary Table for 2017 ........................................................ 16 


\section{Introduction}

The National Renewable Energy Laboratory (NREL) has conducted numerous biodiesel research and development projects over the last 20 years in collaboration with industry technical experts from the diesel engine, aftertreatment, vehicle manufacturer, and the biodiesel industry. The industry's current research focus has spawned questions on the current state of biodiesel quality. Biodiesel must meet ASTM International Specification (ASTM) D6751 for quality. Previous studies have shown marked improvements in neat biodiesel (B100) quality over the last 15 years (Alleman et al. 2007; Alleman and McCormick 2008; Alleman et al. 2011; Alleman et al. 2019).

Recently, the Association Quality Management of Germany (AGQM) published quality testing results from German biodiesel producers. In 2017, 15 German biodiesel producers and traders were surveyed for 23 quality parameters in the German biodiesel specification (DIN EN 14214:2014) (Dietrich 2017). The survey collected 53 samples (1,060 data points) from three time periods: winter, intermediate, and summer.

Previous quality surveys have been collaborations between NREL and the National Biodiesel Board (NBB) to conduct third-party sampling of biodiesel in the market. These surveys have been somewhat limited in their scope due to the cost associated with sampling and analytical testing. This study follows the AGQM model, where previously collected analytical data was analyzed. 


\section{BQ-9000 Program}

The data for this study came from companies participating in the BQ-9000® quality program. ${ }^{1}$ The BQ-9000 program combines fuel specifications (from ASTM D6751) and quality systems programs based on ISO 9000. The program covers biodiesel from start to finish, from production and storage to distribution and fuel management practices. There are three designations within the BQ-9000 program: producer, marketer, and laboratory. The program is open to any biodiesel manufacturer, marketer, or distributor of biodiesel and biodiesel blends in the United States and Canada.

Participants in the BQ-9000 program are required to demonstrate that biodiesel produced meets ASTM D6751 and to demonstrate quality assurance, including corrective actions in the event of off-specification product. Required documentation includes quality manuals largely based on ISO 9000. Third-party audits are required for initial accreditation, along with surveillance audits and a three-year recertification audit.

The laboratory used to demonstrate product compliance may be internal or external and must have documented the accuracy of their results through validation testing by an outside laboratory, accurate measurement of standards, or participation in an external biodiesel cross check program. This rigorous requirement for testing ensures laboratories report accurate and precise data.

Samples that are found to have laboratory results out of conformity with a specification must be dealt with following specific procedures, including reprocessing to meet specifications, or being reclassified, or rejected/destroyed. Reprocessed product must undergo retesting to ensure all metrics are satisfied and these steps must be documented.

\footnotetext{
${ }^{1}$ www.bq-9000.com
} 


\section{Methods}

The monthly analytical results for companies participating in the BQ-9000 program are not normally made public. To encourage companies to provide and allow publication of the data, the use of a third-party team to provide a firewall for the information between each company and NREL was developed. This third-party team consisted of Mr. Steve Howell of M4 Consulting, Mr. Scott Fenwick from NBB, and Dr. Richard Nelson of Enersol Resources. This team was tasked with developing an agreement on how to access and provide the data to NREL in a method that was acceptable to all parties.

Once agreement had been reached on how the data would be scrubbed, analyzed, and published, all BQ-9000 accredited producers were asked to provide their existing data on metals and flash point, which are required monthly, as well as the corresponding BQ-9000 critical parameters required on every lot and phosphorous, totaling 14 parameters. Because this is the first effort of its kind in the United States, producers were asked to provide data starting in January 2017, though prior data exists. The data were analyzed on a yearly basis and this is the first of a series of reports on this topic. This reporting timeframe covered changing market conditions, captured plant maintenance events (such as shutdown periods), changing feedstocks, etc. Participation in the survey was strictly voluntary, although Mr. Scott Fenwick confirmed the vast majority of the BQ-9000 companies did provide data.

Producers were asked to supply a single value for parameters from their production lots for each of the 12 months in the calendar year. Per BQ-9000, a biodiesel production lot is defined as a homogeneous production volume of finished biodiesel from one or more sources held in a single container where representative samples are taken and analyzed to provide an authentic certificate of analysis for the specific volume.

After the data were received from the BQ-9000 companies, all company names, plant locations, and dates were scrubbed and the data were anonymized prior to being provided to NREL for analysis. The data collection effort resulted in over 5,000 data points for 2017, with most of the 14 parameters having between 300 and 500 individual results. To minimize the time investment for the BQ-9000 companies, they were asked to provide whatever raw data was easiest to collect and which required minimal effort on their part. No attempt was made to insure a complete data set of the requested parameters from each company.

The vast majority of data received had one value per parameter per month, but some producers reported data that contained more than one data point per parameter per month (equivalent to two or more unique production lots in a single month). In those cases, the third-party team averaged the values for that particular month and only reported the averaged value to NREL. In addition, not all companies had production every month across the 12-month timeframe. Thus, the number of reported data points varies among the parameters of interest.

Upon discussion with Mr. Steve Howell, Mr. Scott Fenwick, and Dr. Richard Nelson, the values reported fell into two categories. In the first category, the actual analytical value was provided (e.g., $137^{\circ} \mathrm{C}$ for flash point). The second category had reported results as "less than" or "greater than" a particular value (i.e. "> $130^{\circ} \mathrm{C}$ " for flash point). For the data contained in the body of this 
report, the data that did not have an actual value wwere removed from the analysis, as the true value of the parameter was not known.

A second analysis of the data was also performed with the "less than" and "greater than" data in the analysis. For this second analysis, the "less than" or "greater than" was simply removed and the value was used in the analysis. (For example, a flash point reported as " $>130^{\circ} \mathrm{C}$ " was assumed to be $130^{\circ} \mathrm{C}$.) Results were analyzed using this format and are presented graphically in the Appendix for informational purposes only.

ASTM D6751 specifies the acceptable specification parameter values, the referee test method used to measure each parameter, and the various accepted alternative test methods. The BQ-9000 program requires the use of one of the approved ASTM D6751 test methods, but no attempt was made to determine the specific test method used from the BQ-9000 companies for this report. The ASTM D6751 specification values and test method options as of 2019 are included in each section that follows. Some values reported from the BQ-9000 companies may be lower than the recommended lower limit of detection of the test method(s). The reported data was included as-is in the data set to calculate the statistics contained in this report, so some caution may be needed in drawing conclusions from the statistics for some of the parameters with values below the published method detection limit. 


\section{Results}

\subsection{Sodium and Potassium}

ASTM D6751 specifies a combined limit of sodium and potassium $(\mathrm{Na}+\mathrm{K})$, using the referee method of European Normalization (EN) 14538. An alternative test method is based on UOP 391, Trace Metals in Organics by AAS. Figure 1 shows the average reported value of $\mathrm{Na}+\mathrm{K}$ was $0.68 \mathrm{ppm}$, and the median value was $0.30 \mathrm{ppm}$. The $95^{\text {th }}$ percentile was $2.23 \mathrm{ppm}$, indicating only $5 \%$ of the data set was greater than this value.

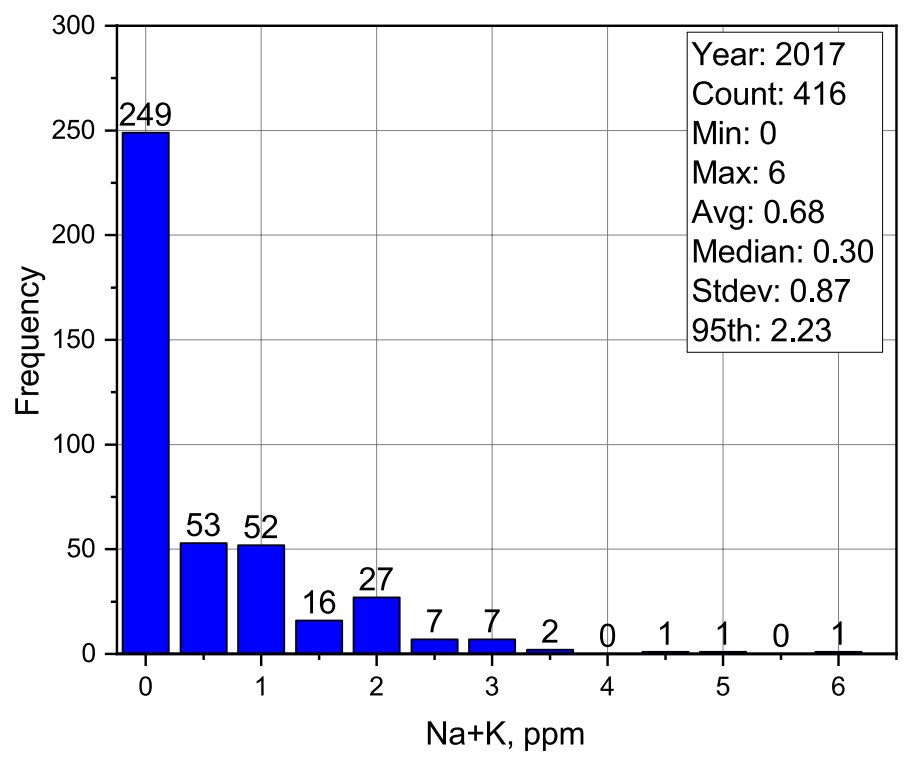

Figure 1. Sodium and potassium content of biodiesel samples, January-December 2017

\subsection{Calcium and Magnesium}

Similar to $\mathrm{Na}+\mathrm{K}$, calcium and magnesium $(\mathrm{Ca}+\mathrm{Mg})$ are reported as a combined value in ASTM D6751. The ASTM D6751 referee test method is EN15438, with UOP 389, Trace Metals in Organics by ICP-OES, listed as an alternate. Figure 2 shows the average reported value of $\mathrm{Ca}+\mathrm{Mg}$ was $0.57 \mathrm{ppm}$ with a median value of $0.06 \mathrm{ppm}$. The $95^{\text {th }}$ percentile of data was 2.00 ppm. 


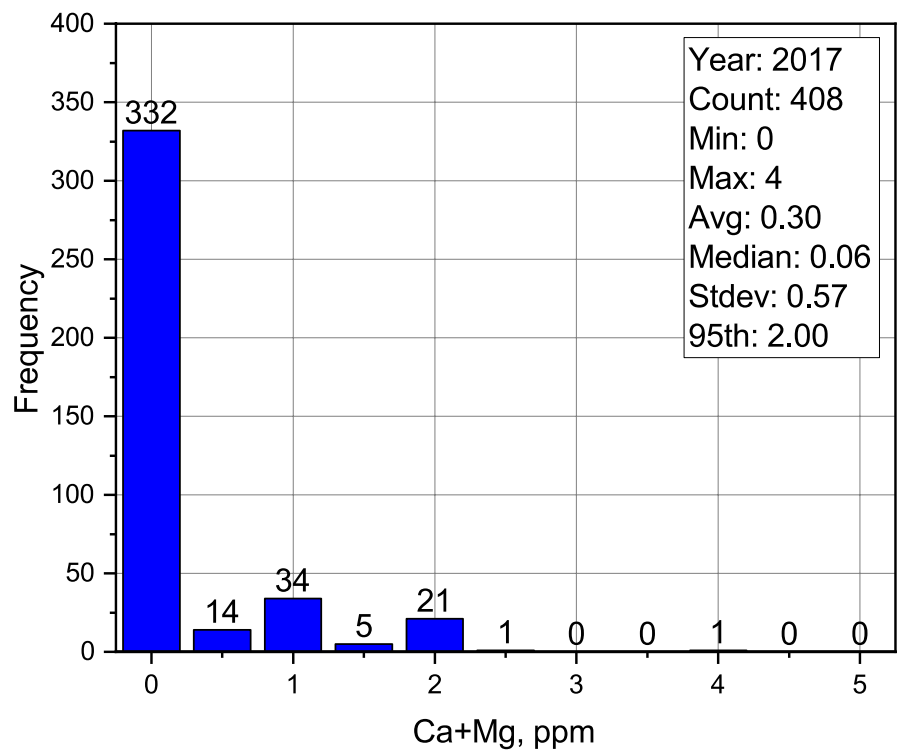

Figure 2. Calcium and magnesium content for biodiesel samples, January-December 2017

\subsection{Phosphorus}

The ASTM D6751 specification limit for phosphorus (P) is 10 ppm, as measured by ASTM D4951. Figure 3 shows the average reported value was $0.41 \mathrm{ppm}$ with a median value of $0 \mathrm{ppm}$. The $95^{\text {th }}$ percentile was $1.00 \mathrm{ppm}$.

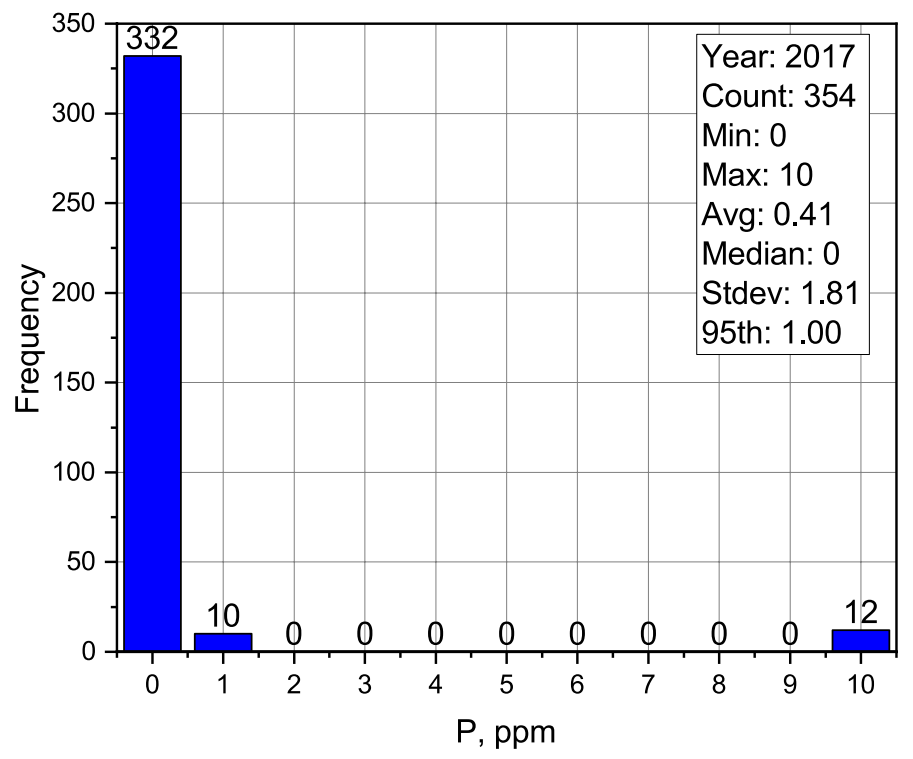

Figure 3. Phosphorus content for biodiesel samples, January-December 2017 


\subsection{Alcohol Control and Flash Point}

The limit on alcohol in ASTM D6751 is an either/or parameter which can be met through direct measurement of methanol content or through the flash point. The methanol content limit in ASTM D6751 is 0.2 mass $\%$ maximum or a minimum flash point of $93^{\circ} \mathrm{C}$. The referee test method for methanol content is EN14110, with an optional test method of American Oil Chemist's Society (AOCS) Standard Procedure Ck 2-09. The flash point referee test method is ASTM D93, and optional methods are ASTM D3828 and ASTM D6450. Samples may alternatively meet only the flash point limit of $130^{\circ} \mathrm{C}$, without measuring methanol content by these same flash point methods.

Figure 4 shows the average reported value of flash point was $155^{\circ} \mathrm{C}$ with a median value of $160^{\circ} \mathrm{C}$. The $95^{\text {th }}$ percentile was $180^{\circ} \mathrm{C}$.

Figure 5 shows the average reported value of methanol content when used for alcohol control of 0.06 mass $\%$ and a median value of 0.06 mass $\%$. The $95^{\text {th }}$ percentile was 0.135 mass $\%$.

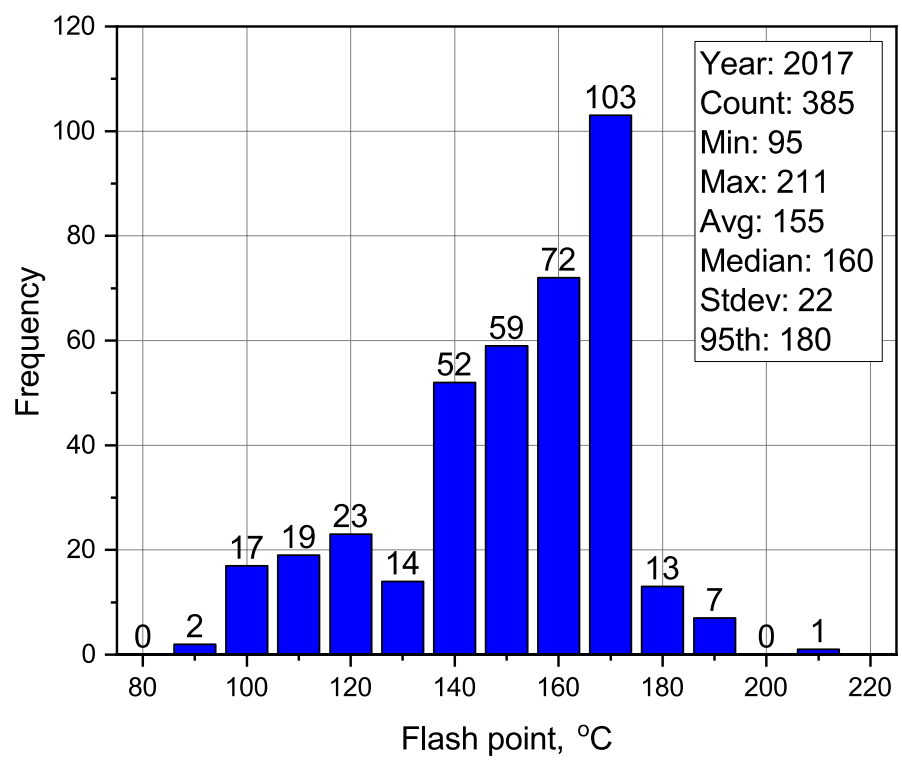

Figure 4. Flash point for biodiesel samples, January-December 2017 


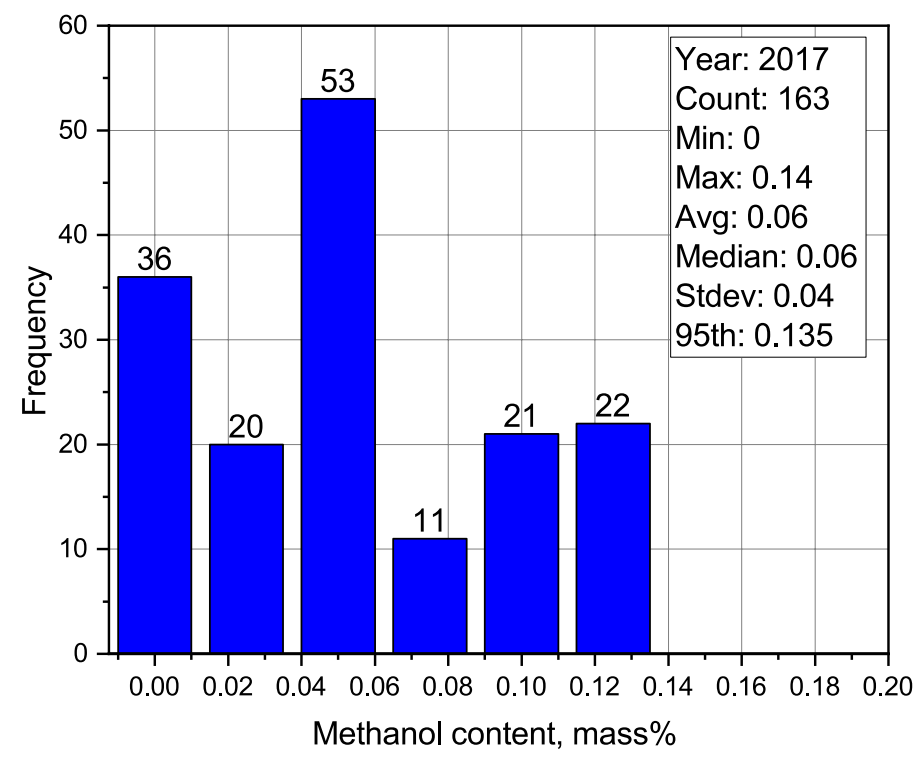

Figure 5. Methanol content for biodiesel samples, January-December 2017

\subsection{Water and Sediment}

ASTM D6751 limits water and sediment to 0.050 percent by volume (vol\%) using ASTM D2709 as the referee method. The alternate method is ASTM D1796. The average water and sediment was $0.020 \mathrm{vol} \%$, and the median was 0 vol\% (Figure 6). The $95^{\text {th }}$ percentile was 0.010 vol\%.

The BQ-9000 parameters also include a requirement that biodiesel is clear and bright. The data set provided included information on this parameter, but since the data were qualitative, it is not presented graphically. All samples were reported to be clear and bright. 


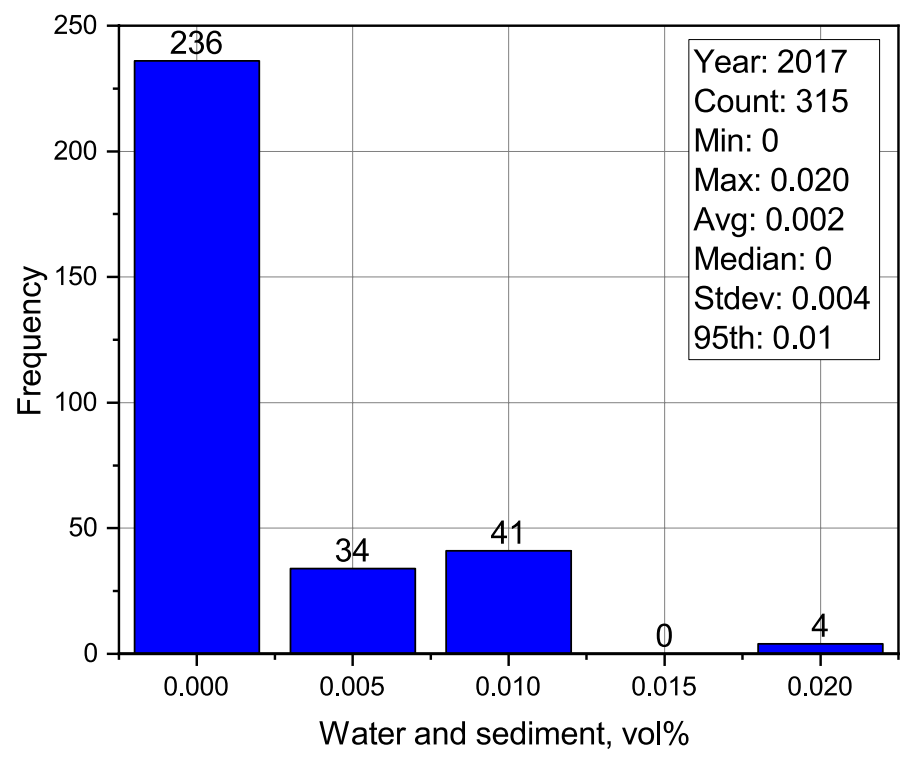

Figure 6. Water and sediment for BQ-9000 producers, January-December 2017

\subsection{Cloud Point}

Within the ASTM D6751 specification, cloud point (ASTM D2500) is a "report" value, meaning there is no specification limit, but it must be tested for and the result reported. Cloud point uses ASTM D2500 for the referee method. Multiple alternate methods are available: ASTM D5771, ASTM D5772, ASTM D5773, ASTM D7397, ASTM D7689, or AOCS Standard Procedure Ck 2-09. The cloud point for the samples, shown in Figure 7, varies from $-4^{\circ} \mathrm{C}$ to $15^{\circ} \mathrm{C}$, with an average value of $0.8^{\circ} \mathrm{C}$ and a median value of $-0.08^{\circ} \mathrm{C}$. The $95^{\text {th }}$ percentile is $9^{\circ} \mathrm{C}$. 


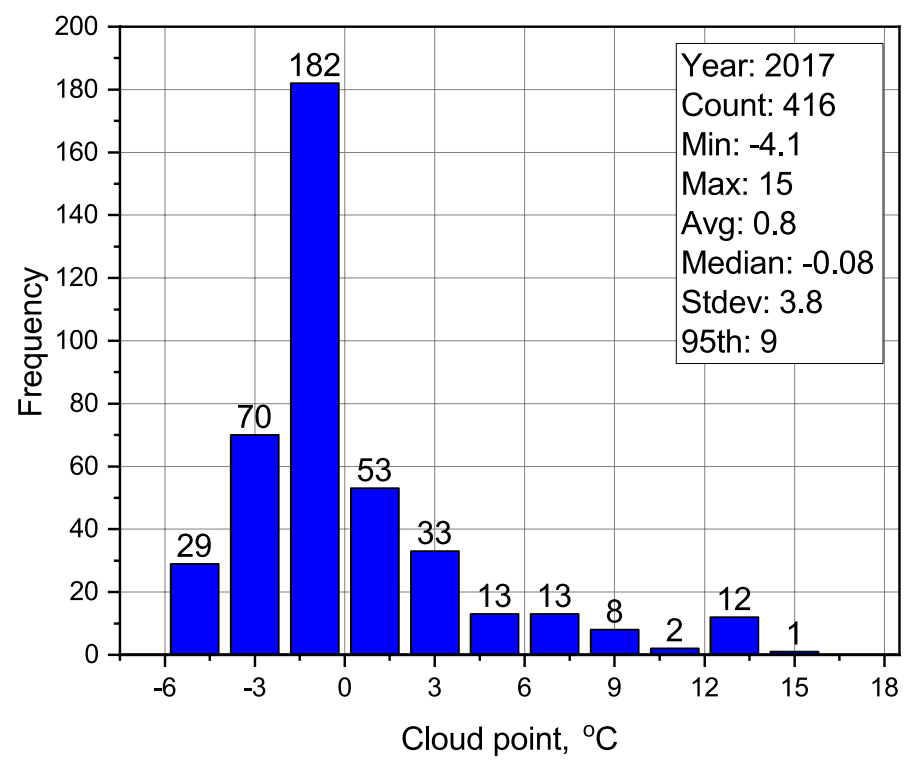

Figure 7. Cloud point for BQ-9000 producers, January-December 2017

\subsection{Acid Number}

The acid number is limited in ASTM D6751 to 0.50 milligram potassium hydroxide per gram (mg KOH/g) using ASTM D664. Two optional methods are listed in the specification: ASTM D3242 and ASTM D974. The average acid number was $0.26 \mathrm{mg} \mathrm{KOH} / \mathrm{g}$, with the median value at $0.27 \mathrm{mg} \mathrm{KOH} / \mathrm{g}$ (Figure 8). The 95th percentile was $0.41 \mathrm{mg} \mathrm{KOH} / \mathrm{g}$.

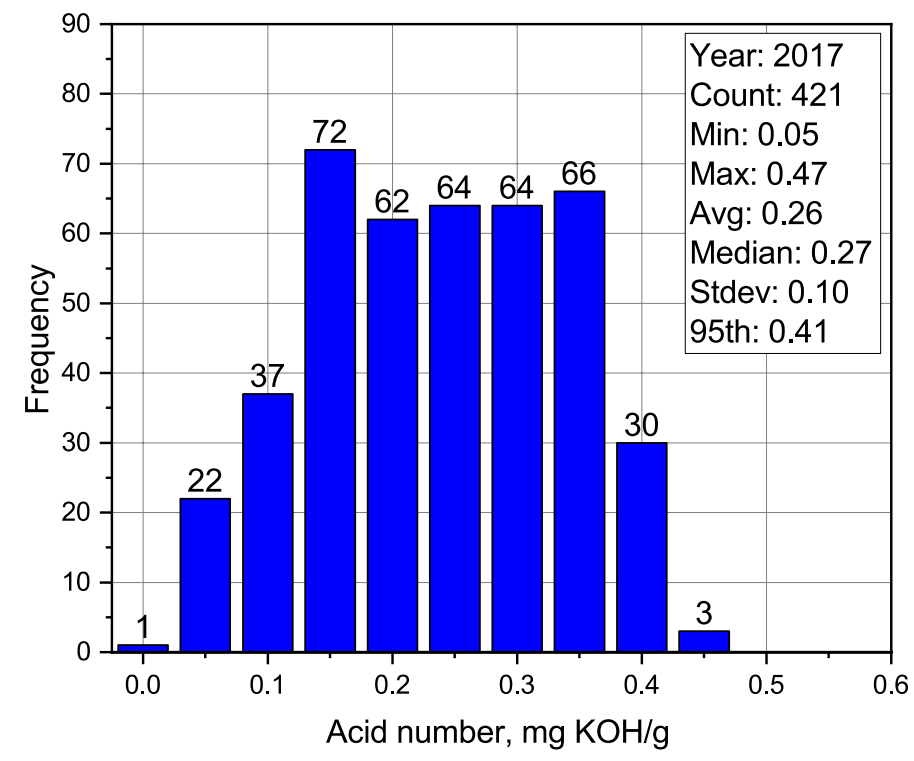

Figure 8. Acid number for BQ-9000 producers, January-December 2017 


\subsection{Free and Total Glycerin}

Free and total glycerin content of biodiesel is measured by ASTM D6584 (referee) or AOCS Standard Procedure Ck 2-09 (alternate), with the ASTM D6751 limits being a maximum of 0.020 mass $\%$ free glycerin and 0.240 mass $\%$ total glycerin. Figure 9 plots the free glycerin, with an average and median value of 0.007 mass $\%$. The 95 th percentile value of 0.014 mass $\%$. The total glycerin is illustrated in Figure 10. Average total glycerin was 0.093 mass $\%$ and the median was 0.103 mass $\%$. The 95 th percentile was 0.151 mass $\%$.

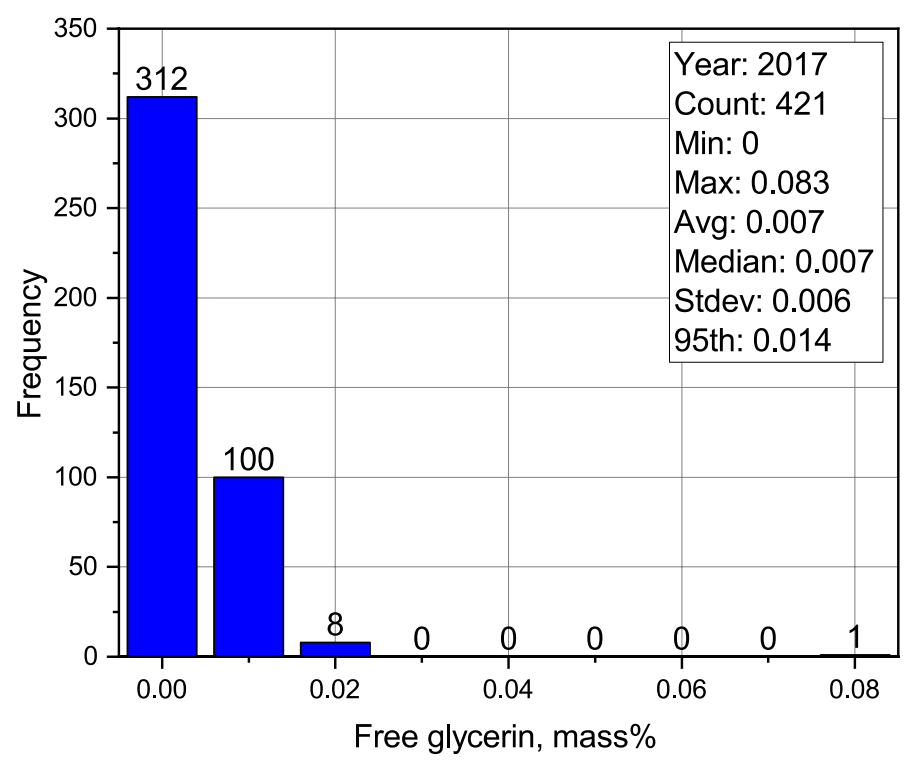

Figure 9. Free glycerin for biodiesel samples, January-December 2017

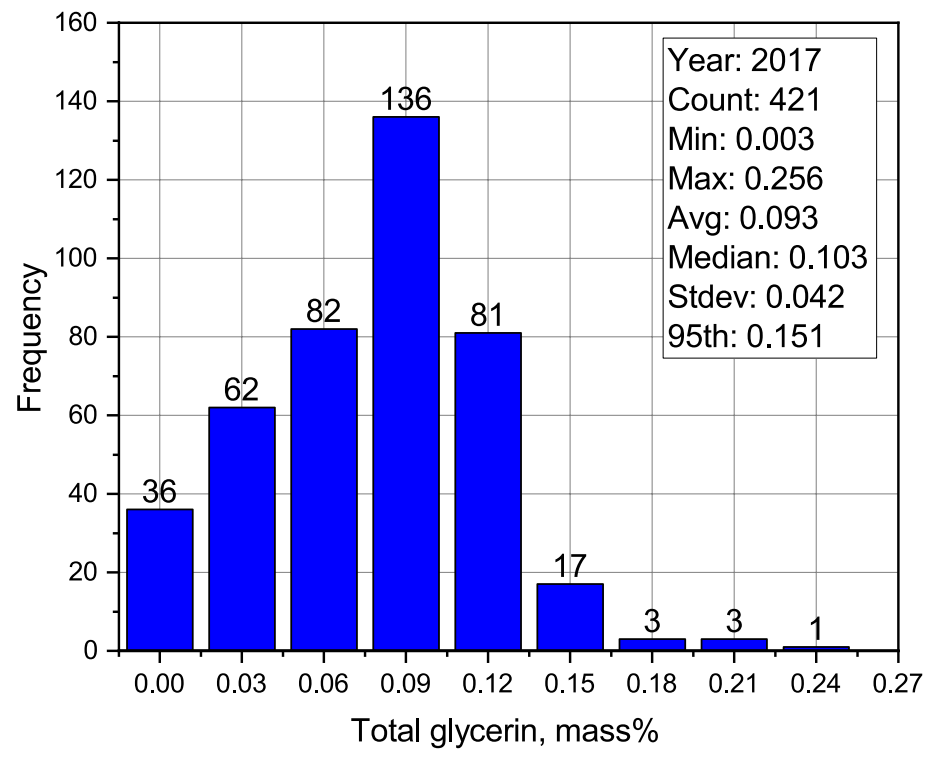

Figure 10. Total glycerin for biodiesel samples, January-December 2017 


\subsection{Monoglycerides}

Monoglycerides (MG) are one component of total glycerin. There is no limit on MG in ASTM D6751; however, there is a voluntary limit for MG in biodiesel meeting the No.1-B grade of 0.400 mass\%. The referee test method for MG is ASTM D6584, and the alternate test method is AOCS Standard Procedure Ck 2-09. Figure 11 shows the average MG content in this study was $0.271 \mathrm{mass} \%$, the median value was 0.299 mass $\%$, and the $95^{\text {th }}$ percentile was 0.436 mass $\%$.

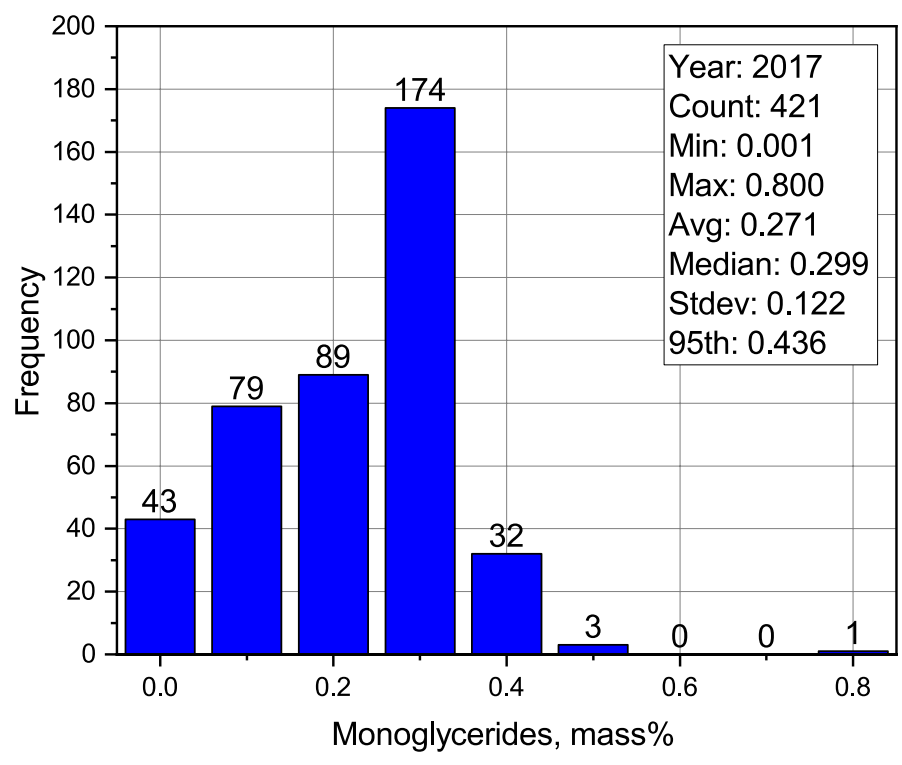

Figure 11. Monoglyceride content for biodiesel samples, January-December 2017

\subsection{Sulfur}

ASTM D6751 allows for two grades of biodiesel based on sulfur content. The S15 grade (ultralow sulfur) has a maximum sulfur content of $15 \mathrm{ppm}$, and the S500 grade (low sulfur) allows up to $500 \mathrm{ppm}$ sulfur by the same test method. The referee test method for both grades is ASTM D5453. For S15, the alternate test method is D7039. For S500, the alternate test methods are ASTM D1266, ASTM D2622, ASTM D3120, and ASTM D4294. Figure 12 shows an average reported value for sulfur of $3.4 \mathrm{ppm}$ with a median value of $1.8 \mathrm{ppm}$. The $95^{\text {th }}$ percentile was $10.8 \mathrm{ppm}$, meaning $95 \%$ of the data was below this value. 


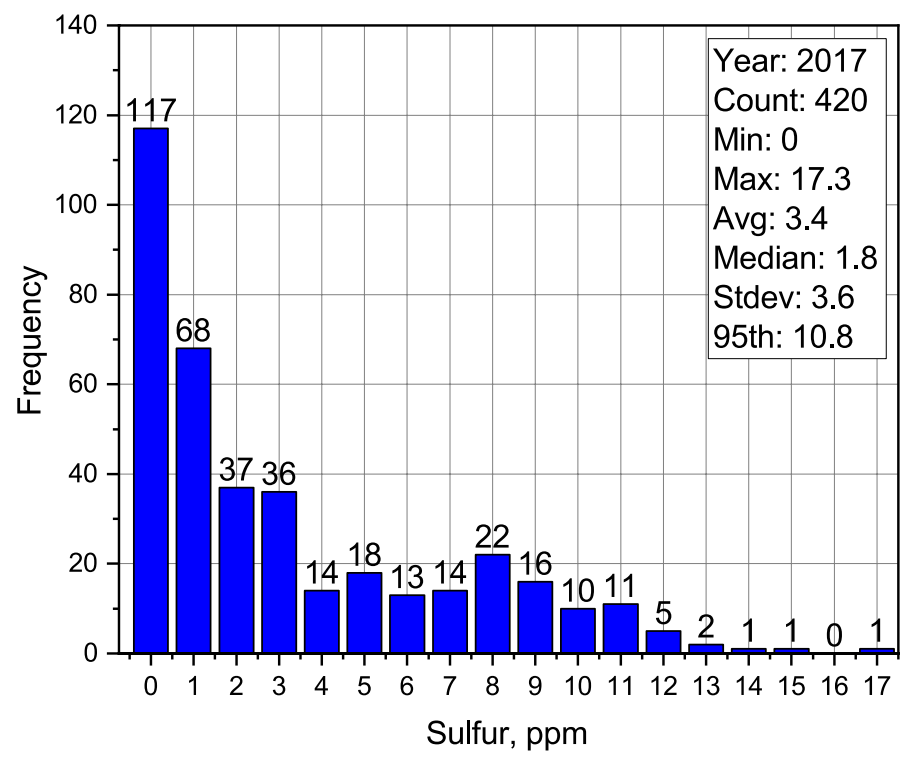

Figure 12. Sulfur content for biodiesel samples, January-December 2017

\subsection{Oxidation Stability}

The referee test method for oxidation stability is EN15751 in ASTM D6751, with a minimum specification limit of 3 hours. The alternate test method for this parameter is EN14112. Oxidation stability for the 2017 samples is illustrated in Figure 13, which shows an average of 9.8 hours and a median of 9.0 hours. The $95^{\text {th }}$ percentile was 17.2 hours and the $5^{\text {th }}$ percentile was 5.2 hours.

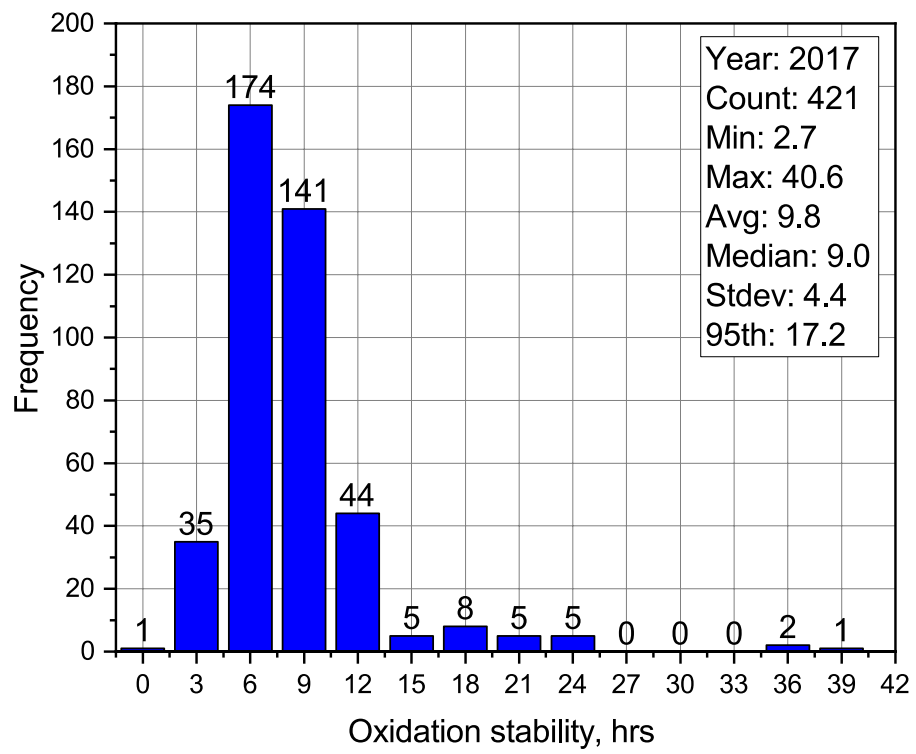

Figure 13. Oxidation stability for biodiesel samples, January-December 2017 


\subsection{Cold Soak Filterability Test}

The CSFT has an upper limit of 360 seconds in ASTM D6751, as measured by ASTM D7501 There are no alternate test methods. The voluntary limit for the No.1-B grade is 200 seconds maximum. The range of CSFT results is provided in Figure 14, which shows an average of 108 seconds and a median of 105 seconds. The $95^{\text {th }}$ percentile was 144 seconds.

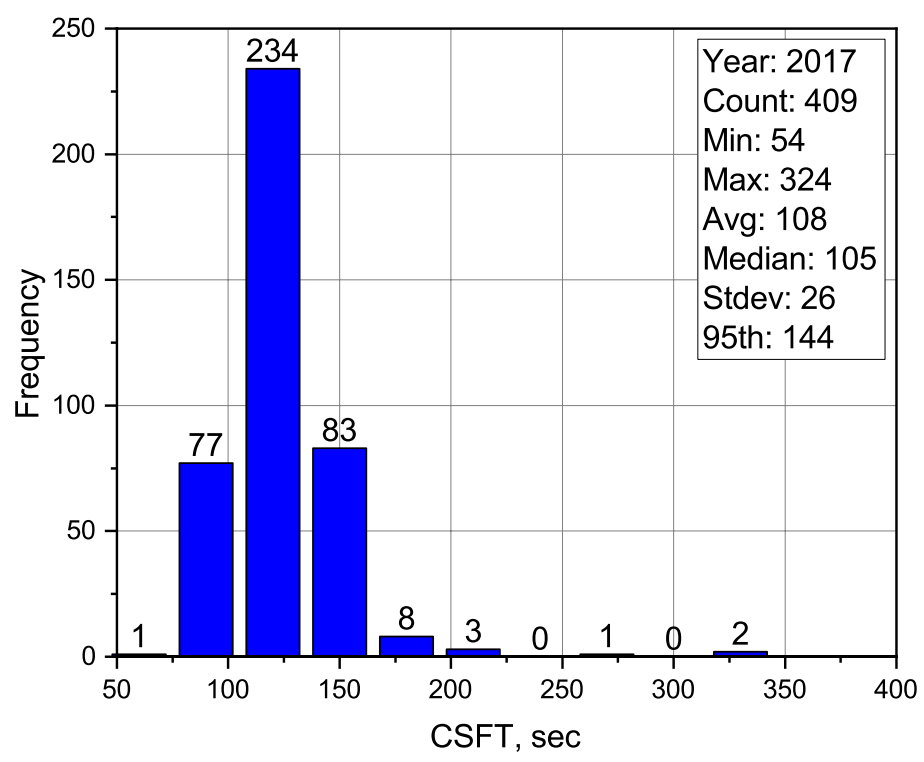

Figure 14. CSFT for biodiesel samples, January-December 2017 


\section{Summary}

This report is the first in a series of planned yearly reports by NREL reporting on the quality of biodiesel produced and sold in the United States in calendar year 2017. The data collection effort was led by Mr. Steve Howell, Mr. Scott Fenwick, and Dr. Richard Nelson who worked closely with biodiesel producers to voluntarily participate in the BQ-9000 program, the biodiesel industry's quality program. The monthly data for each unique production lot, was scrubbed of identifying information and randomized for analysis by NREL.

The data set included the following critical quality parameters: metals $(\mathrm{Na}+\mathrm{K}, \mathrm{Ca}+\mathrm{Mg}$, and $\mathrm{P})$, flash point and alcohol control, water and sediment and visual appearance, cloud point, acid number, free and total glycerin, MG, sulfur, oxidation stability, and CSFT. Analysis of the data reveals that in 2017, reported parameters for biodiesel overwhelmingly met the ASTM D6751 specification limits. Average, minimum, maximum, and $95^{\text {th }}$ percentile data are summarized in Table 1. In all cases, the $95^{\text {th }}$ percentiles of the data were well in excess of minimum specification limits for flash point and oxidation stability and fell well below maximum limits for metals, alcohol control, water and sediment, acid number, free and total glycerin, sulfur, and CSFT. 
Table 1. BQ-9000 Critical Parameter Summary Table for 2017

\begin{tabular}{|c|c|c|c|c|}
\hline $\begin{array}{l}\text { BQ-9000 } \\
\text { Parameter }\end{array}$ & Minimum & Maximum & Average & $\begin{array}{l}95^{\text {th }} \\
\text { percentile }\end{array}$ \\
\hline $\mathrm{Na}+\mathrm{K}, \mathrm{ppm}$ & 0 & 6.00 & 0.679 & 2.23 \\
\hline $\mathrm{Ca}+\mathrm{Mg}, \mathrm{ppm}$ & 0 & 4.00 & 0.301 & 2.00 \\
\hline $\mathrm{P}, \mathrm{ppm}$ & 0 & 10.0 & 0.411 & 1.00 \\
\hline Flash Point, ${ }^{\circ} \mathrm{C}$ & 95 & 211 & 155 & 180 \\
\hline $\begin{array}{l}\text { Alcohol Control, } \\
\text { mass \% }\end{array}$ & 0 & 0.14 & 0.06 & 0.135 \\
\hline $\begin{array}{l}\text { Water and } \\
\text { Sediment, vol\% }\end{array}$ & 0 & 0.020 & 0.002 & 0.01 \\
\hline Cloud Point, ${ }^{\circ} \mathrm{C}$ & -4.1 & 15 & 0.800 & 9 \\
\hline $\begin{array}{l}\text { Acid Number, } \\
\mathrm{mg} \mathrm{KOH} / \mathrm{g}\end{array}$ & 0.05 & 0.47 & 0.26 & 0.41 \\
\hline $\begin{array}{l}\text { Free Glycerin, } \\
\text { mass } \%\end{array}$ & 0 & 0.083 & 0.007 & 0.014 \\
\hline $\begin{array}{l}\text { Total Glycerin, } \\
\text { mass } \%\end{array}$ & 0.003 & 0.256 & 0.092 & 0.151 \\
\hline $\begin{array}{l}\text { Monoglycerides, } \\
\text { mass \% }\end{array}$ & 0.001 & 0.800 & 0.271 & 0.436 \\
\hline Sulfur, ppm & 0 & 17.3 & 3.4 & 10.8 \\
\hline $\begin{array}{l}\text { Oxidation } \\
\text { Stability, hrs. }\end{array}$ & 2.7 & 40.6 & 9.8 & 17.2 \\
\hline $\begin{array}{l}\text { Cold Soak } \\
\text { Filterability Test, } \\
\text { sec }\end{array}$ & 54 & 324 & 108 & 144 \\
\hline
\end{tabular}




\section{References}

Alleman, T.L., L. Fouts, and E.D. Christensen. 2019. Metals Analysis of Biodiesel Blends.

Golden, CO: National Renewable Energy Laboratory. NREL/TP-5400-72341.

https://doi.org/10.2172/1511818.

Alleman, T.L., L. Fouts, and G. Chupka. 2011. Quality Parameters and Chemical Analysis for Biodiesel Produced in the United States in 2011. Golden, CO: National Renewable Energy Laboratory. NREL/TP-5400-57662. https://doi.org/10.2172/1071952.

Alleman, T.L. and R.L. McCormick. 2008. Results of the 2007 B100 Quality Survey. Golden, CO: National Renewable Energy Laboratory. NREL/TP-540-42787.

https://doi.org/10.2172/925707.

Alleman, T.L., R.L. McCormick, and S. Deutch. 2007. 2006 B100 Quality Survey Results. Golden, CO: National Renewable Energy Laboratory. NREL/TP-540-41549.

https://doi.org/10.2172/908195.

Dietrich, Maren. 2017. Biodiesel Quality in Germany. Sampling results of biodiesel producers and warehouse operators of Association Quality Management Biodiesel (AGQM). Neusaess, Germany: ASG Analytik-Service GmbH. https://www.agqm-biodiesel.com/application/files/ 5515/2464/7963/QualityReport 2017.pdf.

McCormick, R.L., T.L. Alleman, M. Ratcliff, L. Moens, and R. Lawrence. 2005. Survey of the Quality and Stability of Biodiesel and Biodiesel Blends in the United States in 2004. Golden, CO: National Renewable Energy Laboratory. NREL/TP-540-38836.

https://doi.org/10.2172/859909. 


\section{Appendix}

The data presented in this Appendix are provided for informational purposes only. The figures presented below include all data provided by BQ-9000 companies, including data points reported as "greater than" or "less than." Any values reported as greater than or less than $(>$ or $<$ ) were assumed to have the value reported. For example, a CSFT reported as " $<360 \mathrm{sec"} \mathrm{was} \mathrm{included}$ in the analysis with a value of $360 \mathrm{sec}$. Thus, no statistics have been presented for these data. 


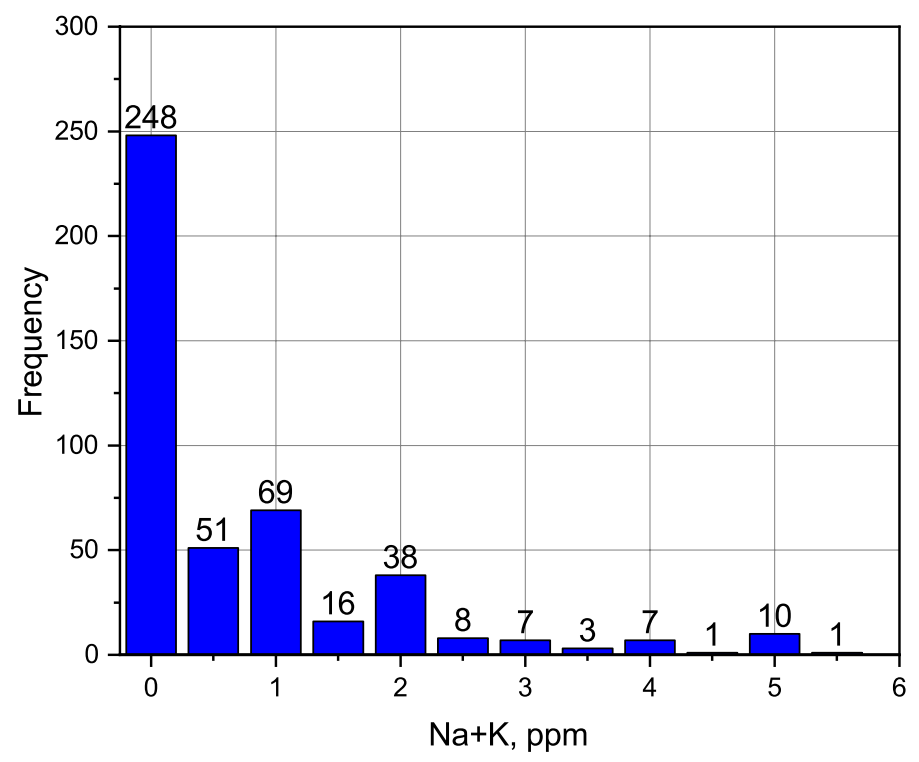

Figure A-1. All data analysis of sodium and potassium for B100 samples produced JanuaryDecember 2017.

Data reported as "greater than X" or "less than X" are assumed to have the value of X.

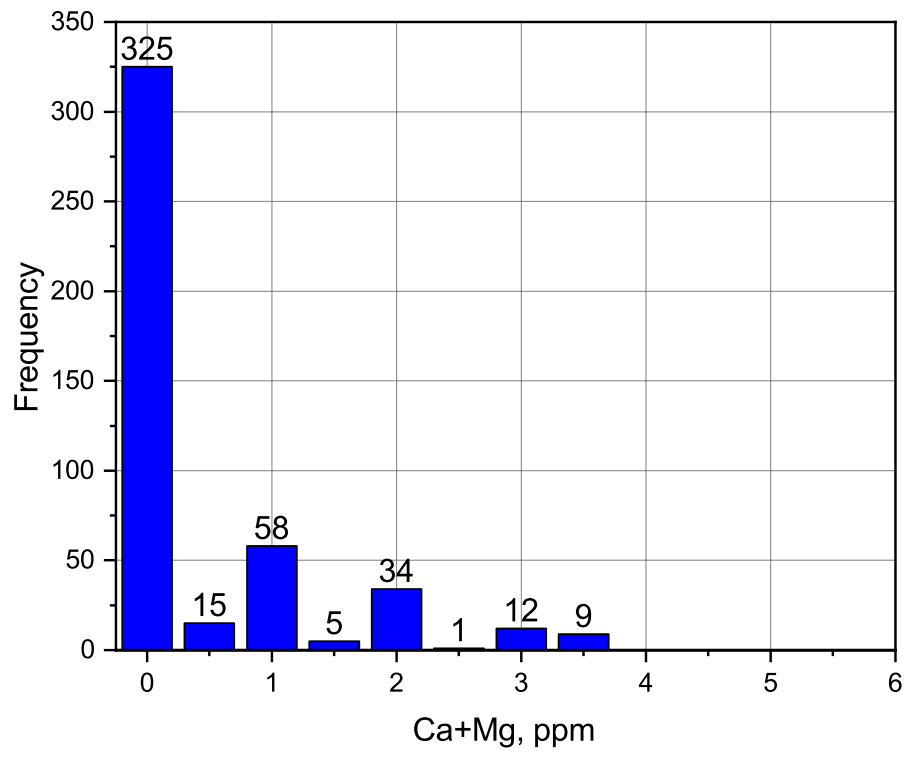

Figure A-2. All data analysis of calcium and magnesium for B100 samples produced JanuaryDecember 2017.

Data reported as "greater than X" or "less than X" are assumed to have the value of X. 


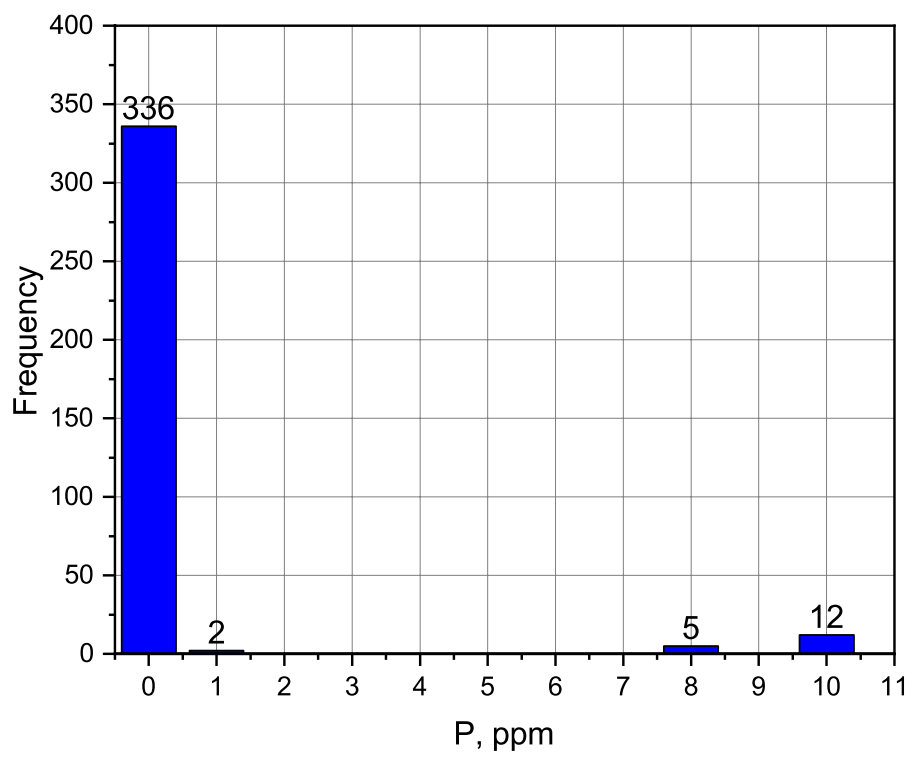

Figure A-3. All data analysis of P for B100 samples produced January-December 2017. Data reported as "greater than X" or "less than X" are assumed to have the value of X.

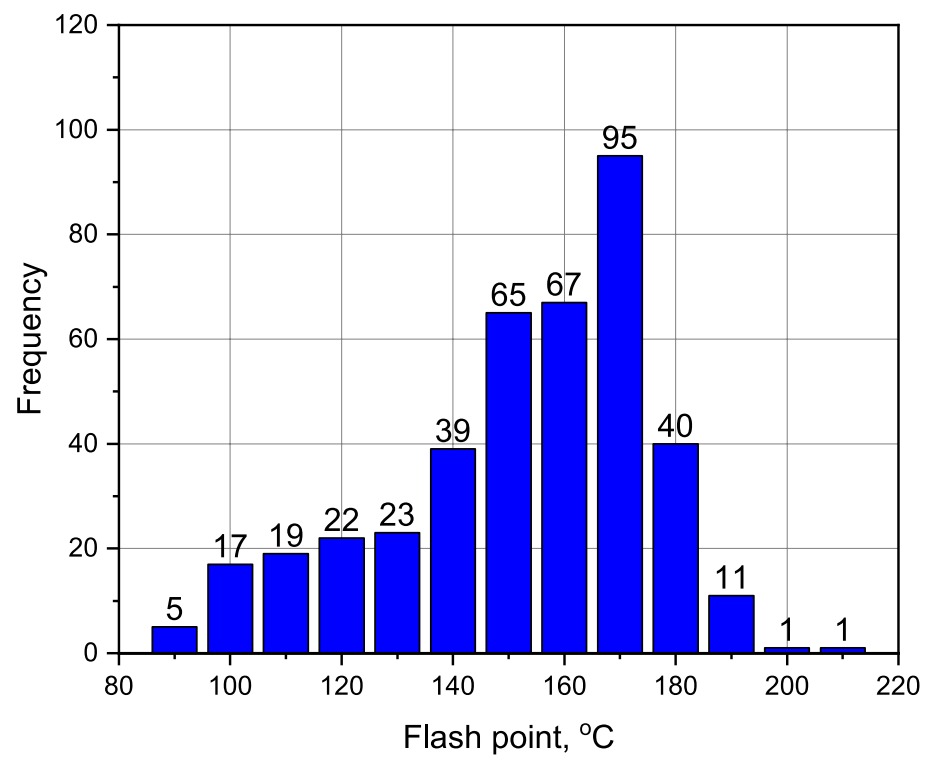

Figure A-4. All data analysis of flash point for B100 samples produced January-December 2017. Data reported as "greater than X" or "less than X" are assumed to have the value of X. 


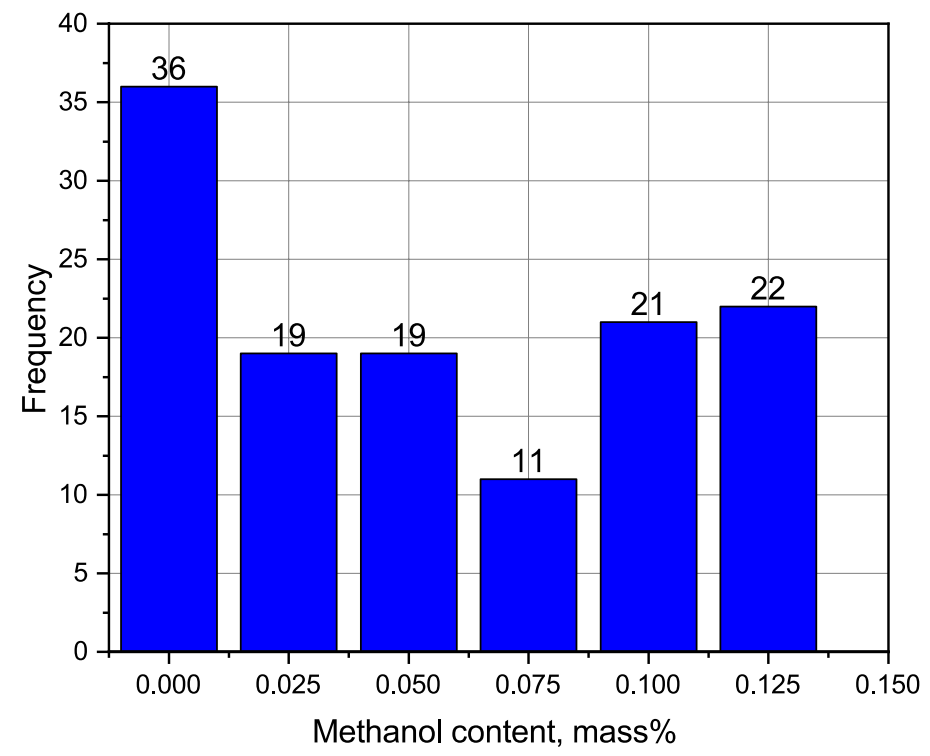

Figure A-5. All data analysis of methanol content for B100 samples produced January-December 2017.

Data reported as "greater than X" or "less than X" are assumed to have the value of X.

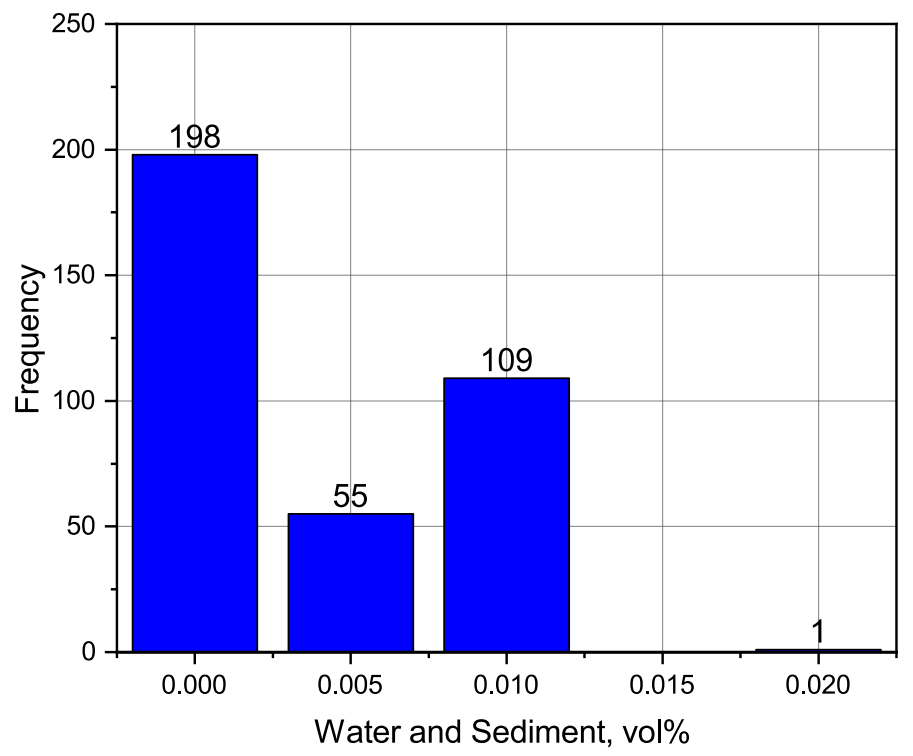

Figure A-6. All data analysis of water and sediment for B100 samples between January-December 2017.

Data reported as "greater than X" or "less than X" are assumed to have the value of X. 


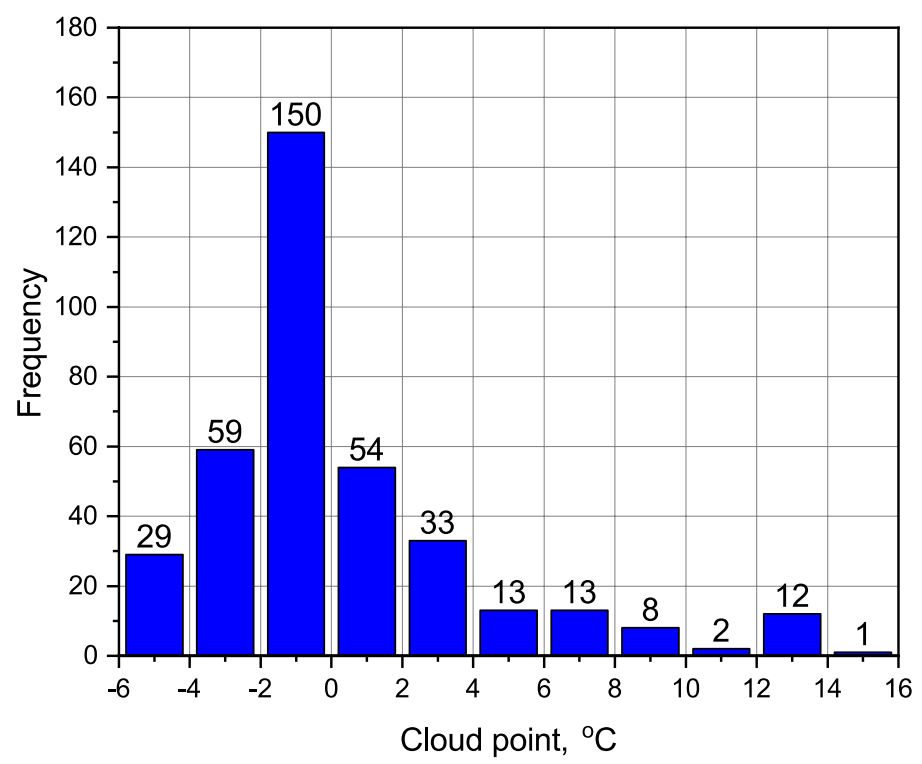

Figure A-7. All data analysis of cloud point for B100 samples produced January-December 2017. Data reported as "greater than X" or "less than X" are assumed to have the value of X.

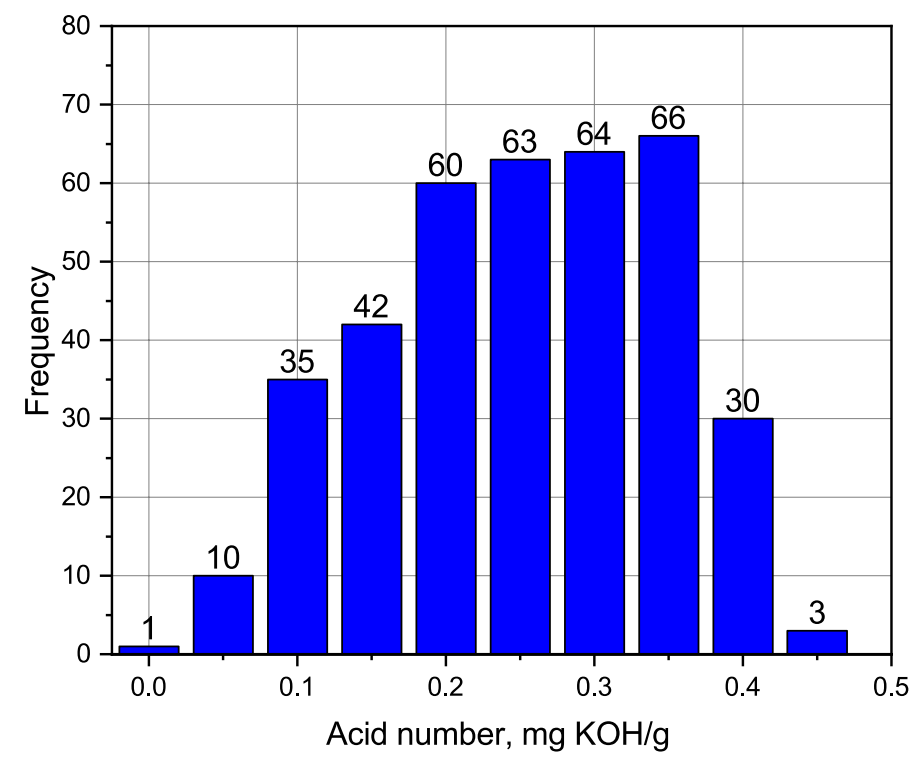

Figure A-8. All data analysis of acid number for B100 samples produced January-December 2017. Data reported as "greater than X" or "less than X" are assumed to have the value of X. 


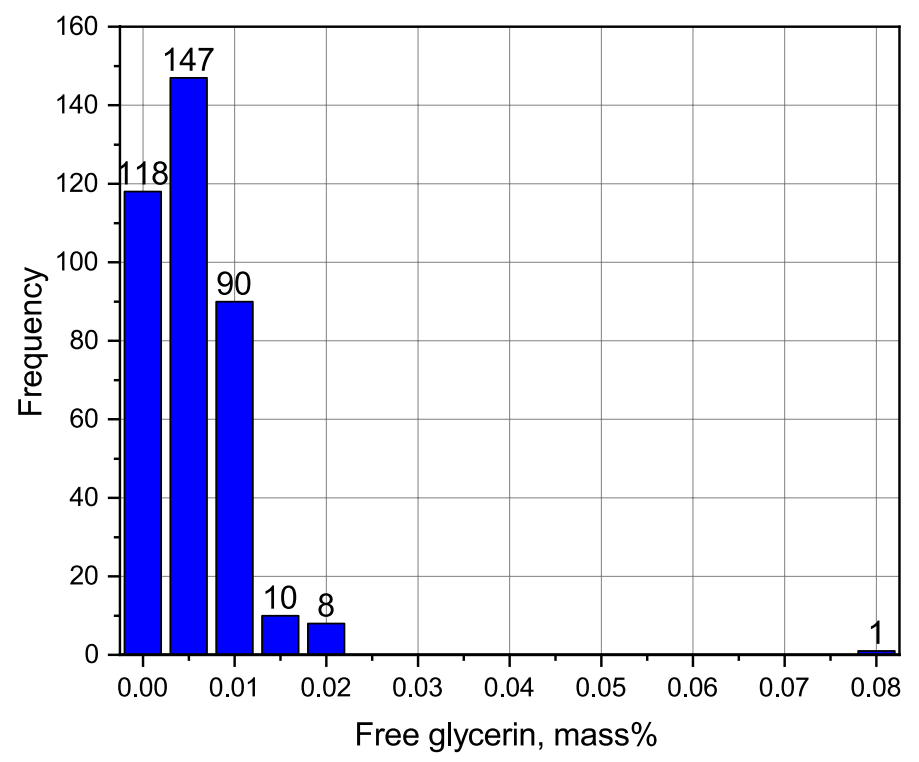

Figure A-9. All data analysis of free glycerin for B100 samples produced January-December 2017. Data reported as "greater than X" or "less than X" are assumed to have the value of X.

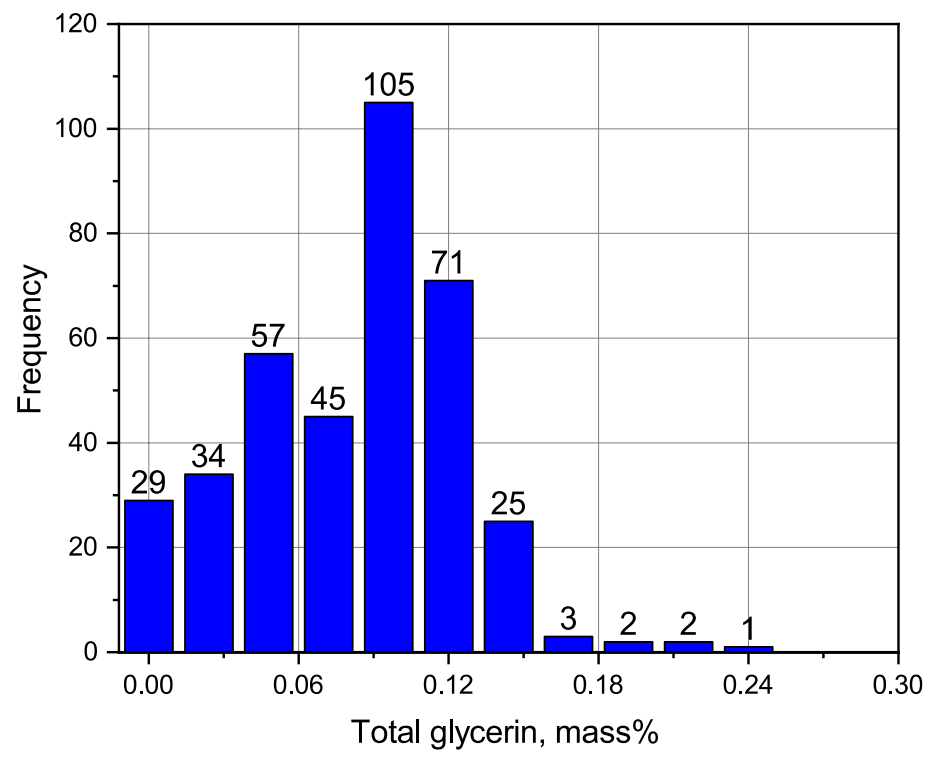

Figure A-10. All data analysis of total glycerin for B100 samples produced January-December 2017.

Data reported as "greater than X" or "less than X" are assumed to have the value of X. 


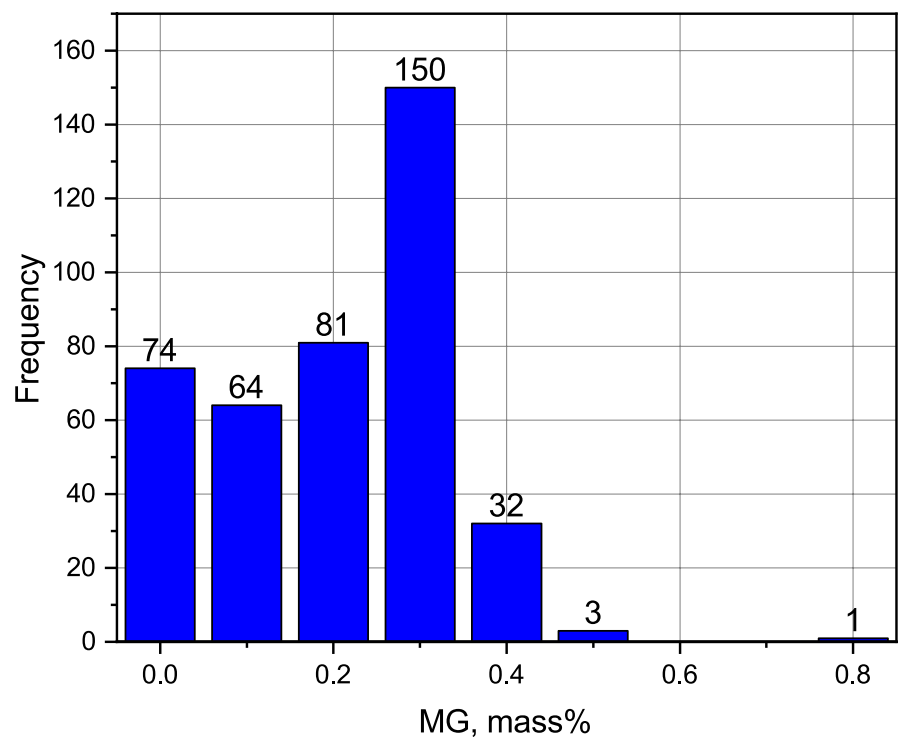

Figure A-11. All data analysis of monoglycerides for B100 samples produced January-December 2017.

Data reported as "greater than X" or "less than X" are assumed to have the value of X.

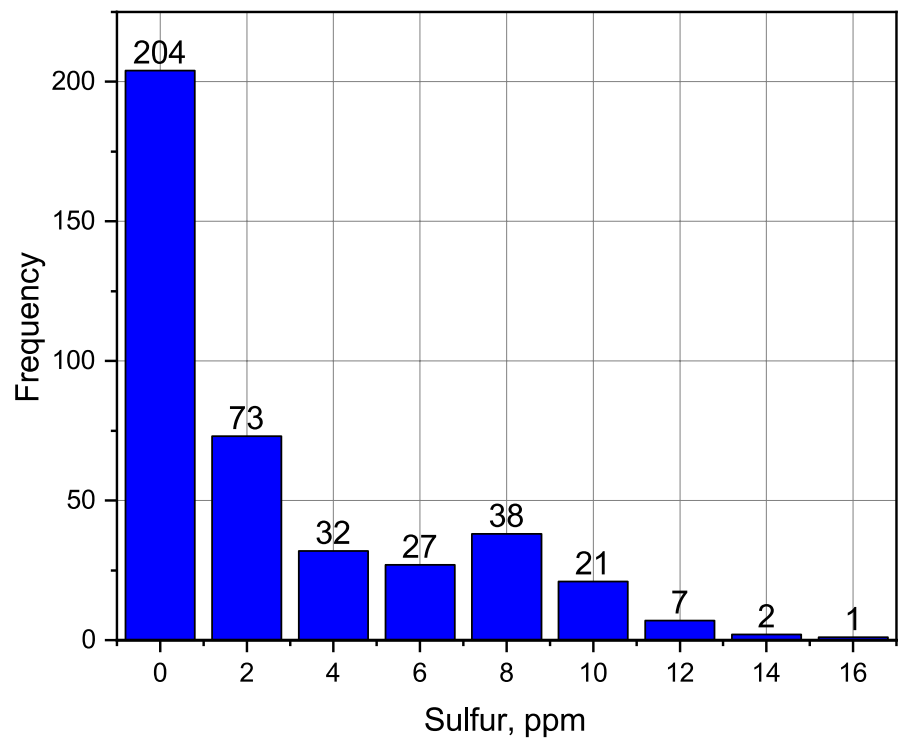

Figure A-12. All data analysis of sulfur for B100 samples produced January-December 2017. Data reported as "greater than X" or "less than X" are assumed to have the value of X. 


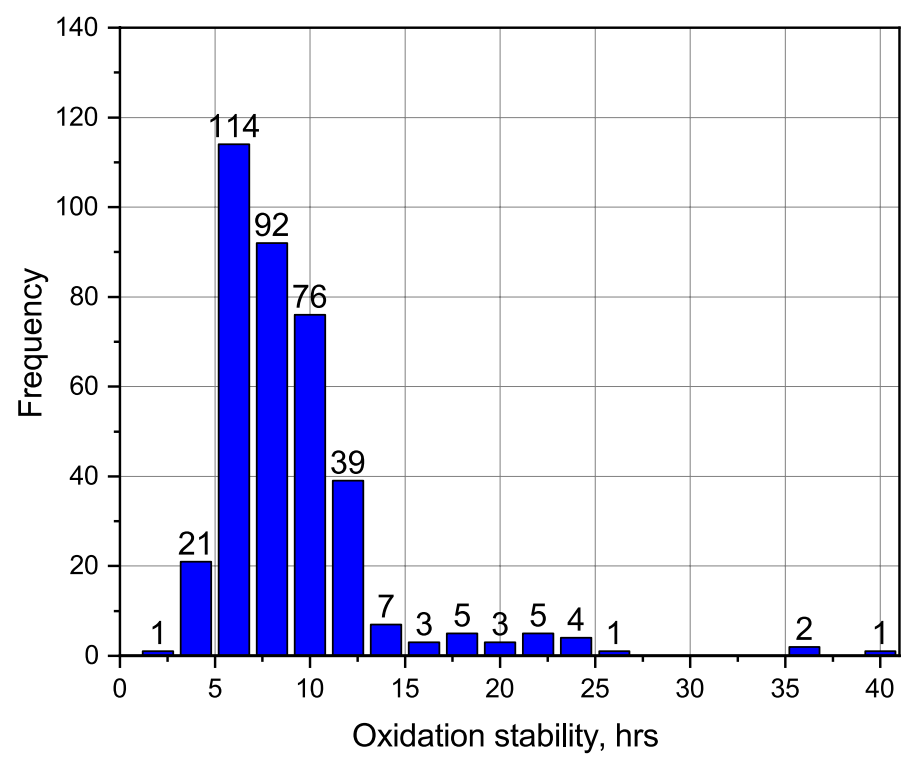

Figure A-13. All data analysis of oxidation stability for B100 samples produced January-December 2017.

Data reported as "greater than X" or "less than X" are assumed to have the value of X.

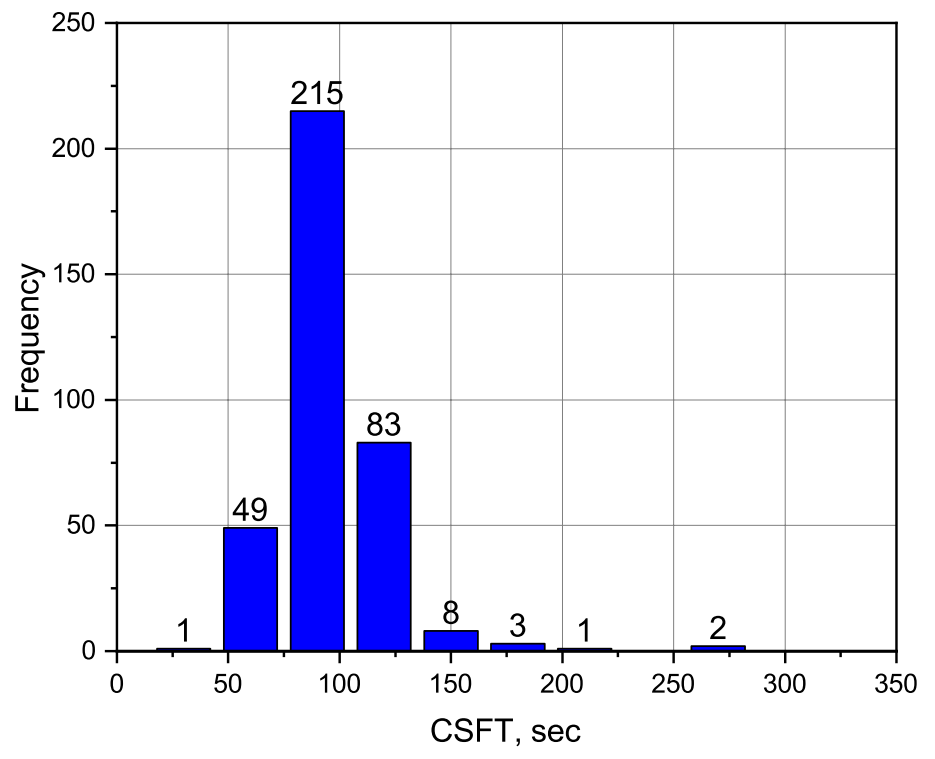

Figure A-14. All data analysis of CSFT for B100 samples produced January-December 2017. Data reported as "greater than X" or "less than X" are assumed to have the value of X. 